\title{
An Elderly with Concurrent Colonic Cancer and Ischaemia
}

\author{
Babiker Ali Babiker Mohammed* and Miadah Difiaa Awad Jiber \\ Department of Surgery, Dallah Hospital, Saudi Arabia
}

Submission: December 11, 2017; Published: January 11, 2018

*Corresponding author: Babiker Ali Babiker Mohammed, Department of Surgery, Dallah Hospital, 7049 Abdul Rahman Ibn Nami-Al Muruj Unit No: 2 Ar Riyadh, 12281-3178, Kingdom of Saudi Arabia, Tel: +966 532880246; Email: waddalomda@gmail.com

\section{Abstract}

A case of acute bowel ischaemia in a 72-year-old female presented to our institution necessitated an emergency surgery. The surgery revealed ischaemic transverse colon and incidentally an adenocarcinoma in the transverse colon just proximal to the splenic flexure. The ischaemic bowel together with the cancer was resected in the same setting. This case emphasizes that a thorough laparotomy is essential because it may reveal another pathology, when treated would improve survival. This operation was performed as a damage control surgery which is important in critically ill patients.

Keywords: Colonic malignancy; Bowel ischaemia

Abbreviations: CVA: Cerebro Vascular Accident; PUH: Paraumblical Hernia; GCS: Glasgow Coma Scale; ECG: Electrocardiogram; CT: AT. ICU: Intensive Care Unit; TPN: Total Parenteral Nutrition; IBS: Irritable Bowel Syndrome; COPD: Chronic Obstructive Airway Disease; HDU: High Dependency Unit

\section{Introduction}

Bowel malignancy is increasing in Saudi Arabia. Now it is the commonest cancer in male and third in females [1]. Despite the high prevalence, still there is not much awareness about colorectal cancer neither among physicians nor among the public. Considerable numbers present late especially with obstruction, up to $45 \%$ [2]. Bowel ischaemia is an uncommon surgical emergency which poses a high morbidity and mortality if not properly addressed [3]. Arterial emboli are the most frequent cause of acute ischaemia. Most emboli are from the heart [4]. Our case presented with these two pathologies, her acute presentation with bowel ischaemia brought her bowel cancer to attention. Moreover, she had a paraumblical hernia which was repaired and diverticular disease which manifested itself as a complication postoperatively with rectal bleeding.

\section{Case Report}

This case report describes a 72-year-old female who presented with upper abdominal pain radiating to the back for one day. It was associated with repeated vomiting. She had a history of constipation on and off for one year. She was known to have IBS but has never had a colonoscopy. She also reported to having palpitations. Past medical history revealed diabetes mellitus, COPD, hypertension, old CVA and was also known to have PUH. Her pulse was irregularly irregular at a rate of 150 beats per minute and the ECG confirmed atrial fibrillation. Her Blood pressure was $145 / 71$, respiratory rate was 25 cycles per minute, and oxygen saturation was $88 \%$ on room air. Abdominal examination revealed an irreducible PUH which was not tender. Bowel sounds were present. Laboratory values showed a hemoglobin of $12 \mathrm{~g} / \mathrm{dl}$, white blood cell count elevated at $20.400 / \mathrm{L}$, and a platelet count of $320 / \mathrm{L}$. Her renal and liver functions tests were within normal limits. Her pancreatic enzymes showed Amylase of 31U/L and Lipase of 21U/L. Her arterial blood gases showed no evidence of acidosis. Abdominal X-ray showed no significant abnormalities.

The patient was admitted as a case of query bowel ischaemia. From the emergency room her atrial fibrillation was controlled and was started on anticoagulation. The CT scan with contrast was performed before the lady became hypotensive and was shifted to ICU where she was resuscitated and prepared for the emergency laparotomy. The result of the CT scan showed diffuse bowel thickening of the transverse colon and gas in the stomach wall suggesting ischaemia, PUH containing omentum only (Figure $1 \& 2$ ).

Intraoperatively the lady was hypotensive and hence a damage controlled laparotomy was performed. During the assessment of the ischaemic segment of bowel a cancer-looking lesion just proximal to the splenic flexure was discovered. The 
ischaemic transverse segment of the colon together with the carcinoma looking lesion near the splenic flexure were resected with stapled closed ends and no anastomosis was attempted. The necrotic omentum was excised as well. The irreducible hernia was reduced by the opening midline laparotomy incision and was found to contain omentum. The fascia was not closed, only skin was closed with clips. The patient was shifted to ICU for a second look laparotomy. In ICU patient was stabilized on inotropes. The heparin was continued and was started on TPN. Two days later the patient was taken to operating room where a second-look laparotomy took place. It revealed no evidence of ischaemia, therefore anastomosis was fashioned, and the abdomen was closed.

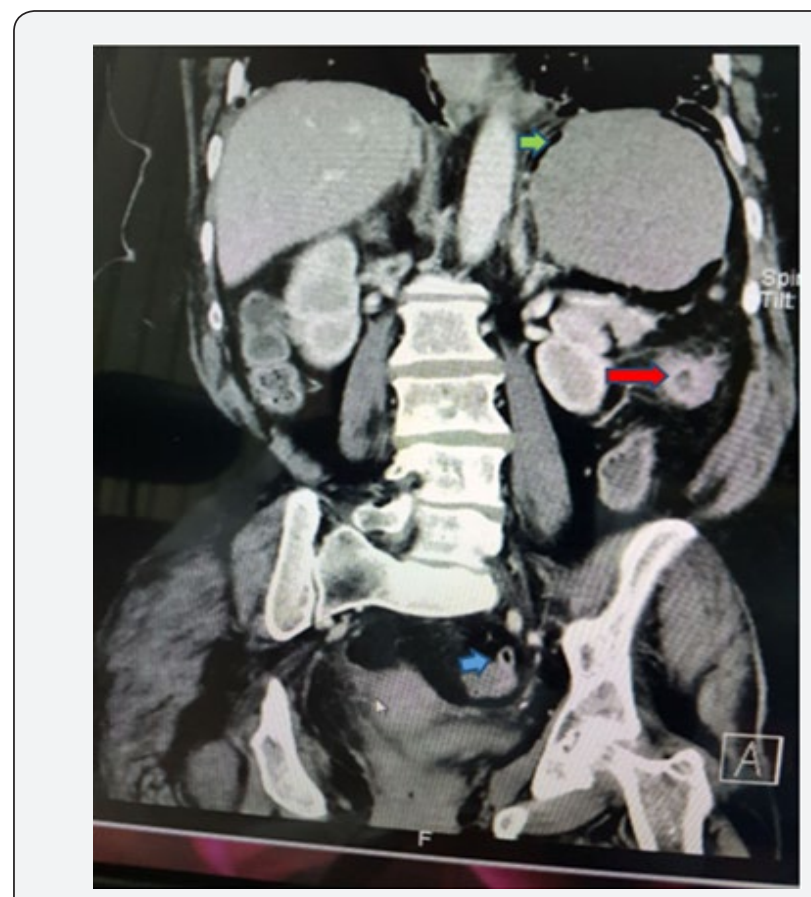

Figure 1: Ischaemia (green arrow gas in the stomach wall), bowel cancer (red arrow) and sigmoid diverticular disease (blue arrow).

The next day of surgery she was extubated and was doing very well. Three days post-surgery inotropes were stopped. One week postoperatively her bowels opened and enteral feeding was started. Nine days postoperatively she was transferred to HDU for one day and subsequently transferred back to her room. There she developed severe rectal bleeding and needed 4 units of blood transfusion. The upper and lower gastrointestinal endoscopies revealed gastritis and diverticular disease as the most likely cause of the bleeding which stopped spontaneously within a couple of days. She was already on proton pump inhibitors. Two weeks postoperatively mobilization started but it was difficult for her to maintain her oxygen saturation due to her COPD. She developed superficial wound infection which settled with removal of clips, frequent dressings and later secondary suturing. The histology confirmed moderately differentiated adenocarcinoma of the colon. The size of the tumour was $3.5 \times 2.5 \mathrm{~cm}$. Total of 8 lymph nodes were identified in the specimen, one of them was involved with tumour cells. Both resection margins of the bowel specimen were free from tumour. No perineural or lymphovascular invasion was detected. The pathological staging was pT3, N1, MX. She was reviewed in the oncology department and the consensus was not to offer her chemotherapy treatment. Three weeks postoperatively she was discharged home with oxygen therapy and continued physiotherapy. She was reviewed in the hospital two weeks following her discharge. She was asymptomatic and clinically doing very well. A follow up telephone call, a year later with her son, confirmed that she was alive and doing well, as she lost to follow up.

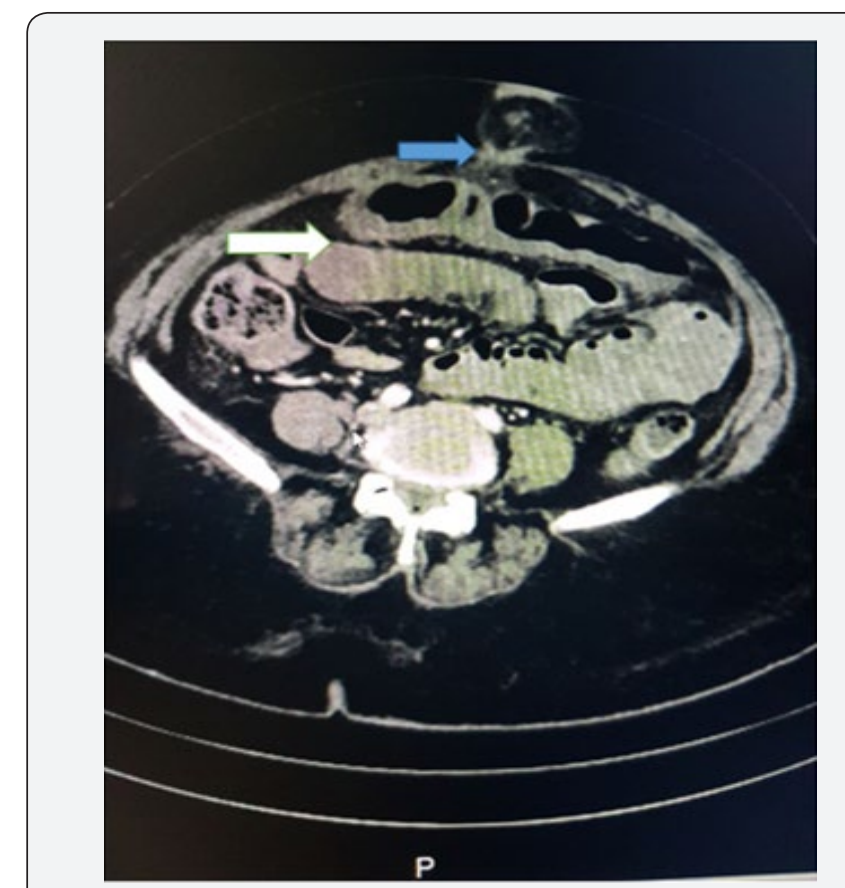

Figure 2: Paraumblical hernia (blue arrow) and ischaemic transvers colon (white arrow).

\section{Discussion}

Bowel ischaemia is a rare condition that present a major diagnostic and therapeutic challenge to the treating surgeon. Acute ischaemia remains a surgical emergency that should be treated by laparotomy and resection of dead bowel in most cases. Acute ischaemia can either be occlusive or nonocclusive. Occlusion can either be due to embolism, thrombosis or iatrogenic. The commonest cause is embolic (50\% of all cases) [4]. Such emboli are usually cardiac in origin, but may arise from atherosclerotic plaques or from arterial aneurysm. The presence of abdominal pain together with atrial fibrillation should alert the physician to the possibility of bowel ischaemia due to emboli as in our case. Colorectal cancer is among the leading cancers in Saudi Arabia [1]. The incidence was rising, almost doubling between 1994 and 2003. In Saudi Arabia, the rising rate of cancer can be attributed to exposure to risk factors, lack of screening program along with aging population [5]

This case is unique in having not only ischaemic bowel and colon cancer but also a hernia and diverticular disease. In 
addition to her multiple pathologies, also the way her operation was conducted underline an important principle in surgery which namely the damage control. This patient had a damage control laparotomy because she was hypotensive. In such scenario if the operation is carried for long time, acidosis, hypothermia or coagulopathy, the lethal triad, will develop. Repeat 'secondlook' laparotomy is an important principle in the management of acute mesenteric ischaemia. The guidelines of the world society of emergency surgery recommend the use of damage control techniques when appropriate to allow for re-assessment of bowel viability prior to definitive anastomosis and abdominal closure [6]. In our case the ischaemia is the reason to bring the patient to hospital and allow cancer treatment.

Early diagnosis of colorectal cancer may be delayed by the wide prevalence of gastrointestinal symptoms in the general population, consequently many physicians underestimate symptoms of abdominal pain, change of bowel habits especially in areas where infectious diseases are still prevalent. Coexistence of colorectal cancer with pathology may lead to an early presentation, as was the case presented. There are many cases in the literature with colorectal cancer and other concurrence in different scenarios. Co-existence of colorectal malignancy and aorto-iliac aneurysmal disease is uncommon, but may be increasing. There is no consensus on the management whether to do the operation for the two conditions synchronously or not [7]. Ischaemic colitis may be associated with partial or complete bowel malignant obstruction. In one reported series, $10 \%$ of patients with colonic ischaemia had an associated colorectal carcinoma, the ischaemic area is proximal to the tumour and may or may not be associated with the obstruction [8]. The speculation is that the colonic blood flow could be decreased as a consequence of increased intraluminal pressure [9].

Colon cancer is seen less where sigmoid volvulus is common, so it is rare for colon cancer to be synchronous with sigmoid volvulus [10]. Some studies have reported that the carcinoma may be a rare predisposing factor for the volvulus. The relationship between sigmoid diverticulitis and colon cancer remain controversial. However, Steffansson et al reported that diverticulitis in the sigmoid colon increase the risk of cancer in the left colon compared with patients with diverticular disease without any clinical signs of diverticulitis [11]. Foreign bodies ingestion has had resulted in the colonic cancer narrow area to obstruct. Dentures had been ingested by elderly patient and caused obstruction [12]. Chicken bone is another example which has caused not only obstruction but rather perforation [13]. This presentation brought a tumour earlier to diagnosis which will otherwise present at a later stage possibly with obstruction and the outcome would be worse.

In conclusion, due to the increased prevalence of bowel malignancy, checking the entire digestive system in any laparotomy considering the possibility of coexisting malignant tumours is recommended. Change of bowel habits in an elderly shouldn't be labelled as IBS, rather colonoscopy is needed which may reveal colon cancer. Damage control laparotomy saves lives in critically ill patients and should always be utilized when appropriate.

\section{Acknowledgement}

The authors would like to express their deep thanks to Dr. Hani Dimassi who reviewed this manuscript. We would like to thank Dr. Jamal Yaqoob for selecting the CT pictures. Authors would like to thank Dr. Nadia Omer, anaesthetist for the competent job she has done.

\section{Conflict of Interest}

a. All the authors declare that there is no conflict of interest.

b. Consent for medical information to be utilized in this report was obtained from the patient son as we lost follow up with her, provided anonymity is respected.

\section{References}

1. National Cancer Registry (2003) MOH, Cancer incidence report in Saudi Arabia, Riyadh, Saudi Arabia.

2. Aljebreen AM (2007) Clinico-pathological patterns of colorectal cancer in Saudi Arabia: younger with an advanced stage presentation. Saudi J Gastroenterol 13(2): 84-87.

3. Oldenberg WA, Lau LL, Rodenberg TJ (2004) Acute mesenteric ischemia: a clinical review. Arch Intern Med 164(10): 1054-1062.

4. Bradbury AW, Brittenden J, McBride K, Ruckley CV (1995) Mesenteric ischaemia: a multidisciplinary approach. Br J Surg 82(11): 1446-1459.

5. Ibrahim EM, Zeeneldin AA, El-Khodary TR, Al-Gahmi AM, Bin Sadiq BM (2008) Past, present and future of colorectal cancer in the Kingdom of Saudi Arabia. Saudi J Gatroenterol 14(4): 178-182.

6. Bala M, Kashuk J, Ernest E, Moore, Kluger Y, et al. (2017) Acute mesenteric ischemia: guidelines of the World Society of Emergency Surgery. World J Emerg Surg 12: 38.

7. Shalhoub J, Naughton P, Lau N, Tsang JS, Kelly CJ, et al. (2009) Concurrent colorectal malignancy and abdominal aortic aneurysm: A multicentre experience and review of the literature. European J of Vascular and endovascular surgery 37(5): 544-556.

8. Boley S J, Schwartz S, Lash J (1963) Reversible vascular occlusion of the colon. Surg Gynecol Obstet 116: 53-60.

9. Boley SJ, Brandt LJ, Veith FJ (1978) Ischemic disorders of the intestine. Curr Probl Surg 15(4): 1-85.

10. Gama AH, Hadad J, Simonsen O, Warde P, Manzione A, et al. (1976) Volvulus of the sigmoid colon in Brazil: a report of 230 cases. Dis Colon Rectum 131: 36-41.

11. Stefansson T, Ekbom A, Sparen P, Pahlman L (2004) Association between sigmoid diverticulitis and left-sided colon cancer: A nested, population-based, case control study. Scand J Gastroenterol 39(8): 743-747.

12. Candia-de la Rosa RF, Garcia RC, Martinez P (2010) Intestinal obstruction due to foreign body in a patient with adenocarcinoma of the colon: case report. Cir Cir 78(1): 87-91.

13. McGregor DH, Liu X, Ulusarac O, Ponnuru KD, Schnepp S (2011) Colonic perforation resulting from ingested chicken bone revealing previously undiagnosed colonic adenocarcinoma: report of a case and review of literature. World J Surg Oncol 9: 24. 
(C) Commons Attribution 4.0 License

BY DOI: $10.19080 / J T M P .2018 .02 .555595$
Your next submission with Juniper Publishers will reach you the below assets

- Quality Editorial service

- Swift Peer Review

- Reprints availability

- E-prints Service

- Manuscript Podcast for convenient understanding

- Global attainment for your research

- Manuscript accessibility in different formats

( Pdf, E-pub, Full Text, Audio)

- Unceasing customer service

Track the below URL for one-step submission https://juniperpublishers.com/online-submission.php 